\title{
LA BIBLIOTECA DEL CANÓNIGO DE VALENCIA DON JOSEPH DE CARDONA
}

\section{Ma. Dolores GARCÍA GÓMEZ}

Universidad de Alicante

\section{Una biblioteca heredada}

Es un hecho conocido que una parte importante de los fondos bibliográficos que constituyeron la Biblioteca Real creada en el reinado de Felipe $\mathrm{V}$ procedieron de las confiscaciones realizadas a destacados austracistas. Una de las aportaciones más nutridas procedió de la confiscación de los bienes del Arzobispo de Valencia, don Antonio Folch de Cardona, poco después de que prestara su reconocimiento al Archiduque Carlos en $1710^{\circ}$. La confiscación, impulsada por la mano de Macanaz, afectó a la importante librería que el Arzobispo había comenzado a organizar en su diócesis ${ }^{2}$.

Sin embargo, fueron varias las reclamaciones que se elevaron acerca de los libros que estaban entonces en posesión del Arzobispo. Los libreros Anisson de Paris se apresuraron a reclamar al confesor real, P. Pierre Robinet, el pago de los libros que el Arzobispo l̇es había solicitado y cuyo importe no se había satisfecho. Los Padres Franciscanos de la Provincia de Castilla la Nueva apremiaron también con insistencia a los bibliotecarios del nuevo establecimiento real para que les fuesen devueitos los libros que Folch de Cardona se habia llevado consigo a la sede valenciana, al considerar que los bienes obtenidos antes de su consagración como Arzobispo correspondían a la orden franciscana. También una familiar del Arzobispo, María Cardona, emprendió la reclamación judicial del importe de los libros que pertenecieron a su tío, el canónigo don Joseph Cardona, y que habian pasado a la librería del Arzobispo de Valencia.

El Fiscal de la Chancillería valenciana, D. Damián Cerdá, a la vista de los testimonios del escribano Victor Salafranca, y de acuerdo con el justiprecio elaborado por los libreros Juan de Baeza y Luis Lamarca, determinó, el 17 de agosto de 1712 , 
que la demandante era acreedora de las 1.817 libras en que fue valorada la biblioteca perteneciente al canónigo Don Joseph Cardona ${ }^{3}$.

En este artículo abordamos el estudio del inventario de la biblioteca del canónigo de la metropolitana de Valencia, Joseph Cardona, situándose su formación entre la segunda mitad del siglo XVII y los primeros años del siglo XVIII. Las tres partes en que puede clasificarse este importante fondo librario presentan matices de distinto carácter ideológico e inquietud cultural, si bien, en conjunto, aportan una variada y rica información bibliográfica que viene a ratificar las definiciones acerca de la existencia de un temprano movimiento renovador en la segunda mitad del Seiscientos valenciano.

Por encima de las particularidades propias de cada grupo o libreria sobresale un criterio único que personaliza y da carácter a esta biblioteca, cuya variedad podría confundirse a primera vista con una mera pasión bibliófila. Un análisis más pormenorizado permite desvelar que la formación de esta biblioteca responde a una afición intelectual con personalidad propia, a pesar de los interrogantes que cabría plantearse. Ignoramos, por ejemplo, si los relacionados en el inventario presentado por Maria Cardona comprendía todos los libros de este clérigo; tampoco conocemos documentalmente el procedimiento ni la fecha por el que los libros del canónigo llegaron a manos del Arzobispo, si bien todo parece indicar que no fue una manda testamentaria, pues es en esa circunstancia en la que se basaba la reclamación judicial de Maria Cardona.

Joseph de Cardona, que aparece incluido entre la relación de nombres que, según F. Aleixandre Tena ${ }^{4}$, llevaron a cabo la labor de censores en Valencia entre 1666 y 1678 - hecho éste que puede contribuir en gran parte a explicar la presencia de algunos títulos de contenido poco ortodoxo que aparecen en el inventario de su biblioteca- fue, además de Examinador Sinodal del Arzobispado, Comisario de la Santa Cruzada, conforme consta en la portada de uno de los Sermones Fínebres publicados por el Cabildo valenciano con motivo de las honras dedicadas al Venerable Padre Domingo Sarrió. Se trata de un sermón apologético fechado en 1677, que ensalza en tres hojas las virtudes que adornaron la vida del Venerable, si bien se hace gala de una exquisita erudición latina, con referencias encadenadas a la historia greca y romana, proporcionando un trato preferencnial a Séneca, Estacio Papino y al ecuménico San Cipriano ${ }^{5}$. Participa también el canónigo en el Sermó de la Conquista con una estampa redactada en valenciano, en la que elogia la "propietat y fecundia ab que parla la nostra llengua materna", y donde se invoca la autoridad y elocuencia de Cicerón, Séneca, Pausanias, Quintiliano y Plutarco, principales fuentes de sus alusiones y referencias literarias e históricas ${ }^{\circ}$. En la introducción a estos sermones se alude al propio Joseph Cardona alabando su erudición: "... en nuestra patria [Valencia] nos dió el tiempo un hombre elocuente [rememorando la invocación ciceroniana de no encontrar un sólo "loquens sapientia"] esclarecido de sangre y virtud, y ha sabido atesorar tanto caudal de doctrina sabiendo distribuirla 
con elocuencia, que se verifica en su sermóm tan lleno de sabiduría, método, propiedad y elegancia"'.

\section{El fondo librario}

Los libros de una biblioteca pueden desvelar en buena parte las aficiones y las inquietudes intelectuales de un individuo, a la vez que pueden constituir también un reflejo fiel de su formación y dedicación porfesional. Pero, el análisis de los contenidos, la especulación acerca de los baremos que son suceptibles de ser aplicados a la interpretación del conjunto de obras que constituyen una biblioteca, no siempre tienen la capacidad de llegar a la concreción que aporta un estudio biográfico contrastado, del que lamentablemente carecemos en el caso de Joseph de Cardona.

En esta biblioteca encontramos algunas de las novedades europeistas que García Martínez, López Piñero, Peset Llorca, Antonio Mestre y Victor Navarro ${ }^{8}$ consideran paradigmáticas del movimiento novator en la Valencia de finales del siglo XVII, pero resultaría más que aventurado afirmar, sin matices, tanto que estas obras fueran reflejo exclusivo de la actividad de comisario inquisitorial y censor de libros, como que se debieran a la inclusión de este personaje en el mundo de las renovadas inquietudes que se asomaban a la Europa culta.

La principal y más novedosa característica de esta biblioteca es la de no ser específicamente humanística, sino la de encontrar también en ella una nutrida representación de libros científicos. Naturalmente, no podían faltar, enlazados con la corriente humanística los libros de renovación espiritual, que demuestran asimismo un interés por las novedades que se gestaban en Europa, y que, conforme van revelando cada vez más estudios específicos, no se hallaban, en realidad, tan lejanas como parecía.

\section{Los libros de ciencias. Las publicaciones europeas}

La biblioteca del deán Joseph de Cardona no puede considerarse propiamente como una biblioteca científica. Sin embargo, la importancia de algunos libros y publicaciones que contiene le dan en este ámbito un carácter singular, incluso extraordinario que, ni siquiera las conclusiones de Peset Llorca o Lopez Piñero, cuando reclaman para el XVII valenciano cierta precocidad en la introducción de las nuevas corrientes europeas, nos hubiesen hecho sospechar.

Lo que hace especialmente atractivo este fondo librario son, precisamente, la aparición de las publicaciones científicas de las Academias europeas, y el número de volúmenes de algunas de ellas, que permite pensar que no respondía a peticiones aisladas sino que obedecían a suscripciones mantenidas. 
La repercusión de estas publicaciones en la actividad científica europea posibilitó el intercambio de los descubrimientos que se lograban en las ciencias", mientras que la inexistencia en España de este tipo de publicaciones nos alejaba del fluir de aquellas novedades ${ }^{10}$. El hecho de que aparezcan en la biblioteca de Joseph de Cardona ejemplares de practicamente todas y más importantes de las que por entonces existían, y algunas de ellas coleccionadas posiblemente desde su aparición -como las alemanas Acta Eruditorum y la Miscellanea Curiosa; la francesa Journal des Sçavants, así como las Actas de la Academia de Ciencias inglesa- manifiestan claramente el interés de su propietario por las novedades cientificas europeas.

Las Acta Eruditorum" aparecieron en 1682 en Leipzig, y fué Leibniz su cofundador e impulsor. Desde sus comienzos, las Acta publicaron las reseñas de libros, al igual que era práctica en su modelo de referencia, Le Journal des Sçavants, aunque también comentaban en artículos -especialmente abundantes en matemáticas, pues procedían de la propia escuela de Leibniz- las novedades científicas, pareciéndose más en esta faceta concreta a las Philosophical Transactions inglesas.

El inventario refleja un sólo volúmen de las Acta, mientras que de Le Journal aparecen catorce ${ }^{12}$. Le Journal salió a la luz en 1665 , al amparo de la Academia de Ciencias francesa y su objetivo, como hemos indicado, era el comentario y resúmen de los nuevos libros. ¿Sería esta la fuente que permitió el conocimiento de las lecturas menos ortodoxas de nuestro deán?. Aunque no era una publicación específicamente científica, sino que atendía a todos los campos del conocimiento, constituyó el punto de referencia y el modelo no solo de las Acta, sino también de las Transactions, que Henry Oldenburg dirigia en Londres al frente de la Royal Society. Si en el campo de la ciencia no alcanzó el papel relevante de las Actas inglesas o alemanas, fué, sin embargo, el vehículo común para la comunicación entre ellas ${ }^{13}$. Los volúmenes reflejados en los asientos de donación y reclamación, que sitúan el marco temporal de pertenencia de la biblioteca al Arzobispo Folch de Cardona, corresponderian a un completo y largo período de esta publicación.

Los doce volúmenes de la Miscellanea Curiosa ${ }^{14}$ que aparecen referenciados si podrian, aunque arriesgando igualmente la hipótesis de sus fechas, corresponder a un largo período de suscripción, ya que esta publicación era de periodicidad anual. La Academia de los Investigadores de la Naturaleza, que dió lugar a la publicación de la Miscellanea, no tuvo la altura de contenido de las Acta leipzinianas o las Philosophical inglesas, pues sus artículos recogian, sobre todo, experiencias médicas y curiosidades naturales, pero no por ello dejaron de tener una merecida reputación baconiana.

Por último las Acta Philosophicae Societatis Regiae ${ }^{15}$, de las que la biblioteca contiene seis volúmenes, le acercarían a las conclusiones de la intensa 
actividad científica desarrolada por la Royal Society desde 1660 , gracias a la labor editora de su Secretario, Oldenburg.

Del conocimiento de los avances científicos que se reflejaba en estas publicaciones dan buena fé los libros de autores europeos que contiene la biblioteca referidos a temas de ciencias naturales, medicina y óptica.

Merece ser destacado en primer lugar, tanto por la repercusión que tuvo en el panorama científico-humanista europeo del XVI como por su primacía cronológica, la obra de Conrado Gesner ${ }^{16}$, erudito y naturalista, iniciador de la taxonomía botánica moderna, ejemplo de como se aunan en sus clasificaciones el respeto a la tradición con la introducción de modernas ordenaciones alfabéticas. Las obras de Gaspar Schott ${ }^{17}$, autor prolífico, estudioso de matemáticas, anatomía, hidráulica, defensor de la experimentación en la línea de Galileo y Atanasio Kircher, es una muestra de los científicos alemanes dados a conocer en el mundo de la ciencia a través de las publicaciones de la Royal Society y Le Journal.

Consecuentemente, podemos pensar que estas obras vehiculares fueran la fuente que permitieron la llegada de estas obras hasta los anaqueles de la biblioteca de Cardona, aunque es problable que sus ambivalentes actividades intelectuales -las ya citadas científicas y las del estudio del mundo subterráneo, que mas adelante comentaremos- suscitaran el interés del canónigo valenciano.

La diversidad de autores que contiene la biblioteca que atienden a varios campos de las ciencia, y la escueta reseña del asiento librario -que con frecuencia se reduce a un vago Opera- hace imposible valorar la presencia de obras concretas. Sirva de ejemplo el caso de Albert von Haller ${ }^{18}$, botánico, fisiólogo, destacado discípulo de Boherave, cuyas obras de anatomía sirvieron de texto en Medicina en la Universidad de Salamanca en $1749^{19}$. Pero igualmente fue autor de una Bibliotheca botánica, y de importantes estudios de historia natural. El inventario de la biblioteca de Cardona no indica el título, pero sería prudente considerar que es más probable que se tratase de su De alii genere naturali, pues fue ésta la que mayor difusión tuvo en el campo de las ciencias naturales, área en la que es más rica la biblioteca de Cardona, en comparación con las obras de medicina. Pero el carácte genérico del asiento no permite sino considerar esta hipótesis como la que presenta mayor probabilidad.

La lectura del inventario completa, lo que aquí sería una prolija relación de otros autores europeos, algunos de ellos relevantes para la ciencia como el profesor de medicina de Praga Nicolas Franchimont ${ }^{20}$, con decisivas aportaciones al conocimiento de los cálculos renales; de Philip Jacob Hartman ${ }^{21}$; del P. Antoine Le Grand $^{22}$, erudito comentador de Séneca, autor abierto a la experimentación en Historia Natural; el prolífico Atanasio Kircher ${ }^{23}$, cuya Ars Magna está considerada, junto con la obra de Schott, un avance importante para la ciencia experimental... 
Todos ellos comparten esa ambigüedad que les hace partícipes de una inquieta receptividad de los nuevos aires, pero también, en otros momentos, mantienen una adhesión a los preceptos tradicionales.

Otros, sin embargo, parecen abandonar definitivamente las antiguas formas, y su inquietud y actividad hacen que puedan ser considerados plenamente modernos, como ocurre con Henry Oldenburg ${ }^{24}$, del que ya hemos hecho mención. Este alemán, padre del movimiento científico inglés, marcó con sus iniciativas la línea que posibilitó desarrollo de la Royal Society ${ }^{25}$. Para Josehp Cardona pudo tener un aliciente añadido, como lo revelan los libros de la biblioteca dedicados a temas ópticos, área que había sido objeto del mayor interés por parte de Oldenburg, de lo que da buena fe su correspondencia con Newton -quien a su vez habia dedicado a este área los primeros cursos tras obtener la cátedra de Barrow ${ }^{26}$. De esta materia aparecen en la librería de Cardona las obras del P. Cherubin d'Orleans ${ }^{27}$, un extenso tratado dedicado a la mecánica ocular, técnicas ópticas, lentes, etc.; asi como la del checo Marcus Marci de $\mathrm{Kronland}^{28}$, autor poco conocido, pero que realizó importantes estudios acerca de la teoría de la mayor refracción de los rayos de luz azul, anticipándose a las experiencias realizadas por Newton; o la de Erasmo Bartholin $^{29}$, autor de los principios de la birrefrigencia frente a la antigua teoría de una sola refracción. De importancia fueron también los trabajos del holandés Jansen $^{30}$, que junto con Lippershey iniciaron la construcción del primer telescopio, asi como la de Antonio Oliva ${ }^{3 !}$, autor singular, considerado como uno de los talentos científicos del XVIII, y que había participado con Borelli en la publicación de los Saggi, crónica científica de la Academia Toscana, y llevado a cabo la recapitulación de los trabajos de Viviani y Galileo y especialmente las de Torricelli, a quien se atribuye la construcción del primer microscopio. Con la elección de estas obras Cardona evidencia sus preferencias en un área que sería una de las más importantes fuentes de los avances científicos del siglo, como ponen de relieve las aportaciones de Newton, Huygens, Boherave y las del propio Oldenburg.

Las obras de autores españoles, ultimamente reivindicados por sus actuaciones en el campo de la ciencia, son las clásicas, destacando las de Caramuel de Loblokowitz ${ }^{32}$ y de Eusebio Nieremberg ${ }^{33}$, por el renombre que alcanzaron, aunque con frecuencia aparecen también en bibliotecas que no muestran especial atención por las ciencias. La de Bustamante de la Cámara ${ }^{34}$ queda alejada, a pesar de su pretensión naturalista, de una auténtica inquietud científica, y sus estudios sobre la historia divina y profana de las serpientes, leones o dragones de las Sagradas Escrituras están más cerca de los bestiarios medievales que de la ciencia moderna.

No obstante, este autor nos da pié para comentar algunos otros libros que también transpiran concepciones medievales, puesto que en la biblioeca de Cardona aparece alguna obra igualmente representativa, especialmente en torno al mundo de la magia o alquimia, cuestiones que también parecen interesar al canónigo de Valencia. 
La magia coexistía a lo largo del siglo XVI con las iniciativas renacentistas que intentaban conocer los misterios de la Naturaleza $y$, si en este último campo aparecen figuras de la talla de Copérnico o de Keppler, también en torno a la alquimia, la magia y la astrología se revelaron talentos de consideración, y no tan lejanos, como ahora nos pueda parecer, de las coordenadas en las que se movía la entonces incipiente ciencia moderna. Despreciar su valor sería un error histórico, pues entre los cultivadores de la magia había verdaderos investigadores experimentales y el ejercicio de las artes ocultas entrañaba una gran dosis de observación de los fenómenos naturales, de acuerdo con patrones empíricos inspirados en verdaderas construcciones teóricas, si bien lejanas todavía, naturalemnte, del paradigma newtoniano. Junto a los grandes nombres de este arte -Teofrasto, Paracelso, Fracastoro, Girolano, Cardano...- otros más oscuros contribuyeron igualmente a estimular la investigación empírica, dado el carácter operativo de este saber ${ }^{35}$. La influencia de esta magia blanca alcanzó a los mismos Bacon, Boyle, Digby, Leibniz y Newton en las experiencias de la todavía no definida física experimental, así como en los campos de la óptica, neumática, magnetismo, etc., y es un buen ejemplo el de Paracelso, cuyos trabajos de temática farmacológica lo entroncarían con la posteriormente llamada ciencia de la química ${ }^{36}$.

Las obras referidas a estos temas contenidas en la biblioteca resultan expresivas del interés de Cardona. Allí están las obras de los europeos Johan G. Godelman ${ }^{37}$, M. Pexenfelder ${ }^{38}$ o Caspar Schott ${ }^{39}$, todas ellas buen ejemplo de la doble luz que proyectaba este arte. Schott, figura destacada en los inicios de la ciencia experimental alemana, estudioso de las matemáticas y la anatomía, también lo era del mundo subterráneo, lo que significó su inclusión en el Índice de Quiroga ${ }^{40}$.

Una obra, registrada en el inventario como Disceptatio a Lapide phisic... $[\mathrm{sic}]^{4 \mathrm{i}}$, sin alusión al autor, nos ha llevado a pensar que se trata del De lapide philosofico, atribuído a Paracelso, y traducido por el valenciano Jacinto Beltrán, según nos informa López Piñero. Su aparición en la biblioteca de Cardona supondría el conocimiento de uno de los autores más representativos de estas corrientes. Pero además de este autor alemán, quien reclama una mayor atención entre este grupo es Giambattista della Porta ${ }^{42}$, autor de la Magia Naturae, que había sido cofundador con el príncipe Federico Cesi, en 1601, de la Academia dei Lincei romana, la primera de estas fundaciones europeas que abrian camino con su espíritu "curioso" a la ciencia moderna. De la Academia romana formó parte el mismo Galileo y, su nombre, de los linces, dejaba bien a las claras el objetivo que se habían marcado al compararse con tan perspicaces animales. La situación de della Porta, como iniciador de esta fundación de carácter científico, sus aportaciones personales al campo de la óptica y de la física -es autor del primer estudio moderno de la física de los gases y vapores-, no excluye la condición de ser también el autor más leido en los temas de magia. 
También algunos autores hispanos participan en esta doble inquietud, como Caravantes $^{43}$, y el popularísimo Martín Antonio del Río ${ }^{44}$ cuyas Disquisitionum magicarum tanto influyeron en la refutación de la magia negra desde la perspectiva de la ortodoxia religiosa. Las veinte ediciones de su enciclopedia sobre la magia, que tantos ataques contiene a la misma, son ejemplo del vivo interès que suscitaba la cuestión, pues, confomre indicaba López Piñero : "... los auténticos novatores se alinearon en ocasiones junto a las pintorescas figuras que encabezaron tal corriente fla de la alquimia o la magia) porque este afloramiento de la subsultura extraacadémica se sumó a la lucha contra las doctrinas clásicas" ${ }^{15}$.

\section{Humanismo y renovación}

Entre los libros del inventario unos, al igual que hemos visto en el caso de las ciencias, destacan por su unidad de criterio. Muchos título pasan por ser comunes en la biblioteca de un hombre culto, pero también buen número de ellos vienen a manifiestar con su presencia el pensamiento y la inquietud del movimiento humanista de talante erasmista. El gusto por la antigüedad clásica, que pervive en el reformismo ilustrado del XVIII, tiene en esta biblioteca de Jospeh de Cardona un buen exponente si consideramos el número de obras dedicadas a la historia y la poesía latina, mientras que otras ponen de relieve también la inquietud erasmista por los estudios filológicos.

Exponente principal es la presencia de la obra del propio Erasmo, la Copia... ${ }^{40}$, que Bataillón define como un ejemplo prototípico de libro de humanidades, y que fue retirado en 1573 por el Santo Ofício de México ${ }^{47}$. Su sóla presencia ratifica la opinión de Fayard ${ }^{48}$ acerca de la frecuente aparición de obras de Erasmo en las bibliotecas hispanas en la segunda mitad del siglo XVII, frente a la manifestada por Domínguez Ortiz cuando se refería a que, después de 1640, se borraria por completo el recuerdo erasmiano.

Si el criterio de Erasmo era que el teólogo debía conocer la técnica filológica, la historia y seguir la autoridad de los Santos Padres, nuestro personaje parece ser obediente discípulo de su doctrina. La presencia de obras de algunos de los Padres de la Iglesia, modelos para el mismo Erasmo, lo ponen de manifiesto. Así, la de San Jerónimo ${ }^{49}$, patrono del humanismo cristiano y a quien el propio Erasmo había aplicado la crítica filológica; o la de San Epifanio ${ }^{50}$, maestro de San Jerónimo en el aprendizaje de las lenguas orientales; o las de San Paulino de Noles ${ }^{51}$, cuya educación clásica le permitió ser considerado un estimado poeta, a quien Erasmo propone como modelo ${ }^{52}$; la de San Bernardo ${ }^{53}$, predicador de la práctica de la oración interior: o la de San Gregorio el Magno ${ }^{54}$ que, en su búsqueda de la tradicion cristiana, fué el primero en acceder a las fuentes históricas merovingias. Estos son, entre otros ${ }^{55}$, algunos claros ejemplos de su atención. 
El número de los registros bíblicos ${ }^{56}$ abunda en esta misma línea de conocimiento de la palabra sagrada. Sin embargo, la dificultad de identificar las ediciones con tan escasa información no hace posible una valoración más concreta. En apoyo del interés por la ciencia escriturística aparecen las Condordantia Biblorum del Cardenal Hugo ${ }^{57}$, obra trascendental y sucesivamente reeditada, y las Correctiones de el Cardenal De Lucca ${ }^{58}$. Las primeras ediciones de algunas de ellas, llevadas a cabo por la abadía de Saint-Maur, enriquecen y califican este fondo librario por su valor documental y las llevadas a cabo en Amberes, en las prensas plantinianas, testimonian también una línea ideológica.

Si el acercamiento a la verdadera palabra de Cristo era el móvil de la actitud que predicaba Erasmo, el instrumento para acceder a ella era el conocimiento de las lenguas clásicas. El interés por la filología clásica sería uno de los fundamentos de los conceptos básicos de la reforma: el latín no sólo era vehículo para el conocimiento directo del pasado, sino también la lengua de la divulgación, la universal, que permitía acercarse a los avances científicos europeos, la lengua de la ciencia y del conocimiento, la lengua de la reforma.

En la cultura latina calmaba el humanismo su sed de conocimiento del pasado. Ejemplos para los humanistas hispanos habían sido Boecio, Séneca y Petrarca $^{59}$, desde cuya filosofía se podía iniciar la imitación de Cristo ${ }^{66}$. Junto con éstas, otras obras están imbuídas también de este espíritu: los escolios a los dísticos catonianos $^{61}$ de Martín García, también propuestos por Nebrija en sus Libri Menores... de poesia latina, son buena muestra del gusto por los autores del maestro de Rotedam. Todavía cabría añadir, aunque con muchas reservas acerca de su identificación, a Marcelino Amiano, a quien el propio Erasmo recomienda para el estudio de la Historia de Augusto ${ }^{62}$.

Otros ejemplos de autores estudiosos latinistas - Pontano $^{63}$, Muret $^{64}$ o Solino ${ }^{65}$, cuyo Thesauro, con grabados y mapas en madera del valenciano Pedro Juan Olivar, alcanzaba una notable belleza a juicio de Palau- complementan el fondo clásico.

Este grupo es de una excepcional riqueza respecto al resto del conjunto librario. Tanto en poesía, con las obras de Cicerón, Ovidio, Virgilio, Juvenal, Marcial $^{66}$, Papino Estacio, Publio Valerio Máximo, Claudiano, Tertuliano, Diogenes Laercio $^{67}$ y un Corpus Veterum Poetarum -que creemos puede ser el De Veterum Poetarum Temporibus de Vosio ${ }^{68}$-, como en historia, con las obras de Tácito, Tito Livio $^{69}$, Lucano, Suetonio, Plinio - ¿no había explicado Nebrija en Alcalá su Historia Natural anticipándose al propio Erasmo?-, Quinto Curcio o Dionisio de Halicarnaso $^{70}$, entre otras muchas de las que nos informa la lectura del inventario, deja constancia sobrada del interés de Cardona por este área. Un interés tan atento a los consejos de Erasmo que no aparecen en su biblioteca las obras de Cátulo 
Propercio o Tíbulo, autores reprobados por el humanista de Rotterdam, aunque se contamine por otra parte con de las de Ovidio o Virgilio ${ }^{71}$.

La concisa reseña referida a los diccionarios, al igual que en casos anteriores, no nos deja mucho margen para aventurar siquiera su contenido, que sólo un muy contados casos aparece especificado ${ }^{72}$. Entre éstos destaca la obra de Charles Ducange $^{73}$, uno de los autores guía de los humanistas hispanos, cuya aportación a la erudición filológica podría absolver el pecadillo de otras ausencias. Junto a ella, las Instituciones... hebreas del Cardenal Belarmino ${ }^{74}$, hombre puente entre la antigua y la nueva religiosidad, de formación escolástica, pero también amigo de Galileo, y que manifiesta actitudes críticas frente a tradiciones inamovibles: la edición de sus Institutiones en las prensas plantinianas reitera el carácter de su contenido. Completa esta línea humanista la obra del filologo holandés Gerardo Vosio ${ }^{75}$ quien, junto con Scaliger, presentaba Mayans como ejemplos de la renovación que necesitaba el pensamiento hispano ${ }^{76}$. Aparecen también las historias de Eliano ${ }^{77}$, y un estudio de Dioscorides - al que se añade el interés de haber sido el erasmista Andres Laguna el traductor y crítico textual del mas reconocido autor de información botánica de la antiguedad - y también figura en el inventario la de Maluenda ${ }^{78}$, cuyos conocimientos del griego y el hebreo propiciaron los comentarios a ediciones de la Vulgata.

Otros libros corroboran y dan cohesión a este área, especialmente los dedicados a la exégesis.

Sin embargo, otros aspectos de la librería del canónigo valenciano reclaman otro comentario, porque si el elegante humanismo de este religioso sólo diera fe de una formación intelectual, difícil sería explicar otras presencias, y los libros de ciencias son un buen exponente de que su curiosidad le pedía desvelar otras novedades.

La inclusión de ciertos títulos hace pensar en la posibilidad de que se relacionase o conociera alguno de los núcleos renovadores del prerreformismo valenciano. Pero, lo que en otros casos no sería tan facilmente comprobable, como resulta en éste, es el hecho de que esa apertura le llegara por medio de la abundante información que recibía por las publicaciones europeas. Si además era o no miembro de alguna de las tertulias que reunían a aquellos espíritus inquietos que iniciaron la renovación científica valenciana ${ }^{79}$ escapa a las posibilidades de nuestro trabajo, aunque la evidencia de su personal fuente, le da un carácter propio.

La obra del jesuita Jean Bolland ${ }^{80}$ cuyo método marco una línea de critica textual -bolandismo- al aplicarla a la descripción de la vida de los santos, es un buen ejemplo. No es posible ante su escueto asiento -que se singulariza en el inventario por el comentario del interés por esta obra de Folch de Cardona, recogiéndola antes que el resto de la librería- precisar si se trata del Thesaurus 
Eclesiastae... o las Antiquitatis et Sacra at Prophana eruditionis, aunque su alta valoración económica en el inventario, cien libras, nos hace pensar en esta última, que recogía en cuarenta y tres volúmenes una ingente obra crítica.

La elección por la obra de Pierre Gassendi ${ }^{81}$, autor preferido por los reformistas hispanos del s. XVIII, resulta también significatva frente a la práctica ausencia de la de Descartes. Aunque su elección de una de las personalidades más fuertemente empeñadas en la investigación científico-filosófica de su momento podría entenderse como anticartesiana, su valoración ideológica está en profunda conexión con ella.

La muestra de Felipe Labbe ${ }^{82}$, el brillante conocedor de las ciencias discursivas $^{83}$, de las filológicas y de la numismática, igualmente destacado por Mayans como maestro de la crítica histórica ${ }^{84}$, es asimismo expresiva. Bajo la concisa reseña de los nueve volúmenes de su Opera, pueden estar incluídas sus colecciones conciliares y la Bibliotheca bibliothecarum..., los Elogium -obra calificada de jansenista-, o los Elogia Sacra ${ }^{85}$, obra de carácter crítico.

Muestra también por el interés documental de las fuentes es la colección conciliar de Schelestrate ${ }^{86}$, el recopilador de los Concilios constanticenses. La escueta reseña de Concilios Generales ${ }^{87}$ podría atribuirse de nuevo a Labbe, o más improbablemente a las del hispano González Davila, pero el alto precio en el que aparecen tasados, otras cien libras, sólo equiparables a las Acta... de Bolando, y muy por encima del resto, nos hacen pensar en el primero de los mencionados.

Las Opera de Samuel Puffendor ${ }^{88}$, continuadoras de la filosofía cartesinana y de la doctrina jurídico naturalista, conciliador como Grocio entre la defensa del poder absoluto de Hobbes y de la imitación al mismo de Locke, junto con las del Cardenal Bona ${ }^{85}$, son otros ejemplos de obras claves en la renovación que, junto con las de Fleury, Bossuet, Nicole o Holl, serían básicas en los planteamientos del reformismo hispano ${ }^{90}$. A éstos se podrían añadir las obras, en una línea poco ortodoxa y de anticipada revisión, las de Hugo de Saint $\mathrm{Cher}^{91}$, ejemplo de revisión del verdadero sentido de la exégesis, y guía para los comentarios de las Sagradas Escrituras; y las del agustino Chretien de Wulf, conocido como Cristiano Lupo ${ }^{92}$ cuya amistad con el Cardenal Noris presupone planteamientos renovadores.

Pero no debemos olvidar que si estos autores, Bolland, Gassendi, Hugo, Labbe, Bona, Puffendorf o Lupo, se situan en posiciones más o menos transigentes, siempre críticas y pocas veces condenadas, ninguno de ellos llegó a plantear una abierta heterodoxia religiosa. Esta relativa moderación contribuyó a que pudiesen ser adoptados como norte y guía del reformismo hispano del siglo XVIII.

Joseph de Cardona, según parece indicar la eleción de estos libros, se manifiesta como un hombre de talante inquieto ante un tiempo que se acaba y otro 
que comienza. Su afición a las ciencias ocultas, su cultura humanista, son llaves conlas que penetra en las novedades que aportan los nuevos tiempos.

\section{Algunos datos bibliométricos}

Hemos examinado este fondo librario atendiendo a las distintas materias de que trata, aunque sin llegar a concretar los resultados bibliométricos con criteríos de exigencia definitiva. El carácter formal de la descripción inventarial, sólo atenta a la cantidad o el formato para llevar a cabo el justiprecio de las obras, desaconsejan establecer cómputos e indices, que juzgamos que, en este caso, serían de escaso interés debido a la limitación que el propio invetario impone.

El documento recoge un total de 457 títulos, repartidos en 887 volúmenes, que hacen pueda considerársela una buena biblioteca. El resultado de su valoración, 1.817 libras, arroja una media por libro de 31,07 reales. Si comparamos esta cifra con el precio medio de las obras existentes en la biblioteca personal del Arzobispo Folch de Cardona, la de Joseph de Cardona resulta inferior en 21,27 reales por libro, cantidad que ratifica el alto valor de la biblioteca del Arzobispo ${ }^{93}$. Sin embargo, la de Joseph Cardona resulta significativamente importante si se tiene presente que representa practicamente el doble del precio que Fayard establecia como media, unos 14,11 reales, en ei caso de las bibliotecas del los miembros del Consejo de Castilla ${ }^{94}$.

El orden que aparece en las anotaciones del registro corresponde a la valoración económica, nombre del autor o título de la obra y número de volúmenes que contiene. A estos añadimos un número correlativo para una más rápida identificación en el indice. No hay, salvo en contadas excepciones, orden preestablecido en los cuerpos o estantes de las librerías -algunos autores clásicos, ciertos grupos de canonistas...- y sólo el tamaño agrupa las obras.

EI formato se especifica en todas las obras, por la ordenación đel tamaño en los estantes, junto con la calidad de la encuadernación, en vitela, pergamino o becerro. El mayor número de títulos correpsonde al tamaño folio $-19^{\prime} 30 \%$-, seguidos por los volúmenes en cuarto $-16,12 \%$ - y en octavo $-5,48 \%$ - quedando los de formato en dieciseisavo sólo con el 1,35\%; mientras que los que se consignan sin especificar su tamaños representan el $9,02 \%$ del total.

En ningún caso se expresa el lugar de edición de las obras, apareciendo el año en uno solo ${ }^{95}$, por lo que la identificación resulta imposible, salvo en aquellosa casos en los que la edición anterior al siglo XVIII fue única.

Cuando reseñamos la obra de los autores incluídos en la biblioteca nos referimos a la primera edición conocida de las mismas en los repertorios consultados. En el caso de no haber identificado la obra concreta del inventario, o de venir sin 
especificar el título, por ejemplo cuando aparecen bajo el enunciado general de Opera, hecho frecuente en estas tasaciones, incluso cuando se trata de autores de los que nunca se hizo una recopilación de su obra que correspondiera a este enunciado, optamos por citar los años correspondientes a la vida del autor y el número que se le ha asignado en el inventario.

Prácticamente todas las obras recopiladas están escritas en latín. Sólo hay registradas treinta y una obras en castellano $0^{96}$, dos en portugués $s^{97}$, una en francés ${ }^{98}$ y sólo posiblemente, pues la grafía da lugar a dudas, una en valenciano".

\title{
El inventario
}

\author{
"Memoria de los libros que se llevo el / Ilustrissimo Señor \\ Arçobispo de Valencia / Don Fray Antonio Folch de Cardona de \\ / la libreria de Don Joseph de Cardona / Dean y Canonigo de \\ Valencia son los / siguientes.
}

$\underline{\text { Libras }}$

Estante $1^{\circ}$. Becerro en folio

$\underline{\text { Volúmenes }}$

$\begin{array}{ll}\text { I } & \text { 2L. s. d. } \\ 2 & \text { 3L. } \\ 3 & 2 \text { L. } \\ 4 & \text { 2L. } \\ 5 & \text { 2L. } \\ 6 & \text { 1L. } 10 \mathrm{~s} .\end{array}$

Esperança de Sacra scriptura

expurga .

Idem. Examen historiarum

Verricellus quests morales et legales.

Idem. de Apostolicis missionibus.

Casius de Miseralibus

Estante $1^{\circ}$ Bezarro $4^{\circ}$

7 L. $16 \mathrm{~s}$.

Carderia.Sermones varios en Portugues

Octavario en Portugues

9 L. $10 \mathrm{~s}$.

Amadeus Gimenium

10 2L. $10 \mathrm{~s}$.

Sandeus

11 L. $12 \mathrm{~s}$.

Sermones de Coimbra a Santo/Thomas

de Villanueva en Portugues

12 2L. 12 s.

Piccionardo de novitio oppere

13 1L. 10 s.

Ferrant Cursus Theol.in $3^{\text {a }}$ pe.

$\mathrm{S}$, /Thomas

$143 \mathrm{~L}$.

Blasius.Anathomia Animaliuns

15 1L. 08s.

Valentis paratilla Iuris 
Estante $1^{\circ}$, vit en $4^{\circ}$

16 4L. 10s. Corpus Iuris Canonici

$172 \mathrm{~L}$.

Quintius Cursius de rebus gesti.

$18 \quad 1 \mathrm{~L}$.

Titus libius Commentaria ad/Delphinum

$192 \mathrm{~L}$.

Suetonius illustratus ad usum/Delphini

$202 \mathrm{~L}$.

Juvenalis, Illustratus ad us/sum Delphini

$212 \mathrm{~L}$.

Boetius, illustratus ad ussum/Delphini

$222 \mathrm{~L}$.

Claudianus, illustratus ad us/sum

Delphini

23 2L. 10s.

Martialis, illustratus ad ussum/Delphini

$242 \mathrm{~L}$.

$253 \mathrm{~L}$.

Enmanuelis de censu et auto/ritate conc.Constantinii

Fabri Philosophia

Idem. Sumula Theol.

26 1L. 10s

Idem. de Plantis, et penerationes animalium.

Estante $1^{\circ} \mathrm{p}^{\circ}$ en fol.

Dionisius Cartus

Gaspar Sanches in Scripturan.

Estante $2^{\circ}$ vitte ${ }^{a}$.en $4^{\circ}$

$3020 \mathrm{~L}$

Miscelanea curiosa medicophisica.

Acta eruditorums

Antonius Legrand.Historia naturae

Eduardus Erber de religione.

Boucourt Lux S.mi Roserii

Estante $2^{\circ} \mathrm{Perg}^{\circ}$.en fol.

$35 \quad 1 \mathrm{~L}$.

Alva militia concetionni

36 L. $16 \mathrm{~s}$.

$37 \quad 1 \mathrm{~L}$

Segovia allegationes pro inma/culata conceptione.

Armamentarium seraphicum

Estante $2^{\circ}$ perg. in fol.

En $4^{\circ}$ Bernardini Senensis Opera

Num. $3^{\circ}$ vitella en $4^{\circ}$ 
45 4L. 10s.

Ovidii opera

46 3L. $10 \mathrm{~s}$.

Alexander ab Alexandro

47 2L.

Valerius Maximus

Num. $4^{\circ}$. Becerro en fol.

Theatrum vita humana.

Num. 6.Perg ${ }^{\circ}$.en fol.

$49 \quad 7 \mathrm{~L}$.

Dicastillo de Iustitia; et Iure

Caritius de Verignae beneficii

Garcia disputs. selecta.

$512 \mathrm{~L}$.

$5210 \mathrm{~s}$.

Castillo Crisis Danielica.

53 1L. 16 s.

Estante $4^{\circ} n^{\circ} 2^{\circ}$ perg ${ }^{\circ}$.en $4^{\circ}$

54 1L.

Marcantii Rationale

Lara de aniversariis,et caplliis

55 1L. 10 s.

Idem,compendium vita hominis

$5610 \mathrm{~s}$.

Magaliani Coment.in primun/canticum

Moyeris

57 1L. 12 s.

Lucerna Înquisitorum $\mathrm{Ber} /$ nardini coment.

$58 \quad 06 \mathrm{~s}$.

Belarminus de Scriptoribus Ecclesiis

Estante $4^{\circ}$ num.3 Vitella en $4^{\circ}$

$59 \quad 4 \mathrm{~L}$.

Espistolae Ciceronis adferentium/et

famif.mo

60 4L. $01 \mathrm{~s}$.

Oppera Seneca.

Plinii Historia

Idem, Panegiricus

3

61 4L. 10s.

Idem, Espistola

$632 \mathrm{~L}$.

Porta Opera.

Nicolaus Desmos

66 L. $12 \mathrm{~s}$.

Boetius de Consolatione

Numero $4^{\circ}$.Becerro en folio.

$676 \mathrm{~L}$.

Carleton Theologia

Marcelinus de Piza

Anales Capucinorum,tom $.3^{\circ}$.

69 2L. 10 S.

$705 \mathrm{~L}$.

Gobar Opera.

Numero $5^{\circ}$ perg $^{\circ}$ en fol. 
Estante $5, \mathrm{n}^{\circ} 2, \mathrm{perg}^{\circ}$. en $4^{\circ}$

Num. $3^{\circ}$ vitella en $4^{\circ}$

77 4L. 10s.

Cornelius Tacitus

Titolibio

Martialis

$792 \mathrm{~L}$.

Martirologio Romano

80 1L. 12 s.

81 1L. 02s.

$824 \mathrm{~L}$.

Galberio ephemerides eruditorum.

Medula Buembaum

Biblia Sacra

83 1L. 10s.

$8406 s$.

Benedictus Via Sacra

Hugo pia desideria

85 1L. 06s.

$86 \quad 1 \mathrm{~L}$.

Num $^{\circ} 2^{\circ}$ Perg $^{\circ}$ en $4^{\circ}$

Comei Rethorica.

Amadei Guimeneii

Silos de pintura,et scultura

Budex orarius

Estante 6 num. $1^{\circ}$.Perg ${ }^{\circ}$. en fol.

Corduba Catena in Lib. Regum.

Lucas Burgensis in 4 Evangelia

Monarchia mistica

Zamora Santoralis y quaresma 3

Quaresma y Santoral de Vega

Num. 3.Vitella en $8^{\circ}$

\section{Filcolbusqui opera}

Danielis Bartholi Caracter/hominis

$12 \mathrm{~S}$.

Franciscus Menerarii Equestrium/Delitia.

Martialis epigramata cum notis

Epigrammatum delectus

Lucanus

Josephus Roselinus de Scrupulis

Franciscus Pomei Panteum misticum

Matheu Rufi Oracula Christia/na perfecs.

Prudentius

Tobias Christianum Vademecum 
Num. $4.8^{\circ}$ en fol.

$1063 \mathrm{~L}$.

Carriere digestum fidei et in sacrum

Baseus Flores totius Theol.practics.

Estante 6.num.5.Perg ${ }^{\circ}$. en fol.

109 3L. 10s.

Las Partidas del Rey Dn.Alonso.

Pineda in Job.

Idem, in Eclesiastem

$111 \quad 1 \mathrm{~L}$.

Crux Religionni (s)

Num.6 Perg ${ }^{\circ}$. en fol.

112 2L. 10s.

Opera D. Gregorii

Estante 7. num.2.Perg ${ }^{\circ}$ en 4.

$\begin{array}{ll}114 & 08 s . \\ 115 & 08 s . \\ 116 & 16 s .\end{array}$

Quaresma de Vega

Porevino de officio Curiali

Luca Romanae Correctionis in/Biblis latinis

$117 \quad 12 \mathrm{~s}$.

Muniessa stimulus Concientis

118 IL. 10s.

Quaresma de Mendo, y asumptos predicables

$119 \quad 02 \mathrm{~s}$

Antiguedades de la Iglesia de Segorve

num. 3.vell ${ }^{\mathrm{a}}$. en 4,8 y 16

$10 \mathrm{~L}$.

Le Jornale descavone

num. 4. $\mathrm{Bec}^{\circ}$. en fol. 
$1332 \mathrm{~L}$.

134 3L. 10s.

135 3L.

136 1L. 10s.

$137 \quad 1 \mathrm{~L}$.

138 1L. 16s.

$13910 \mathrm{~L}$.

$1407 \mathrm{~L}$

$141 \quad 11 \mathrm{~L}$.

$14220 \mathrm{~L}$.

143 8L.

144 3L. $10 \mathrm{~s}$.

145 2L. $10 \mathrm{~s}$.

146

147

148 2L. 12s.

7L. $10 \mathrm{~s}$.

1L. $10 \mathrm{~s}$.

$2 \mathrm{~L}$.

1L. $10 \mathrm{~s}$. 08s.

$1 \mathrm{~L}$.

Matheu de regimine

Estante 7 num 5.Perg ${ }^{\circ}$. en fol.

Enao de Sacrificio Missa, et Scien/tia medica

Machado

Amelus de Sacerdotis officio.

Solinus memorabilia mundo

num.6 $\mathrm{Perg}^{\circ}$ en fol.

Opera D. Sivilli

Villalpando in ezechielem

Estante 8.num.1.Vitella en fol. Opera Epiphanii

Opera Jacobi Loletii 7 tom. en

Opera Petavii

Ducange Glosarium

Alliers hierarchia Eclesiastica

Antonii Civilli de regula morum

num.2.Becer.en $4^{\circ}$.

Casalas Candor lily

Tertulianum praedicans

Michael Pexenfelder symbolica/etica, et

ortus Marianus

Paulinus

Sermones S.Vicentii Ferrerii

Antonii Mureti notae in catulium

Biblia Sacra en $8^{\circ}$

Reginaldus de Prudentia/in confesionario

Ancher ortus inscriptiunum

num.3.Vitella.en 4

Gasparis Schoti opera

Carolis Stephani dictionarium

Tyrillus de probabilitate

Bonaspei de probabilitate

Gervasius manuale confessionum

Barisanus magnus Hipocrates/medico moralis

num.4.Becerro en 8.

Labe Opera 
$16 s$.

Casimirus Ordin.suplementum/de

$12 \mathrm{~s}$. Lexiptoribus Eclesiasticis

Luca Dozzii Medicina

1L. 10s.

$2 \mathrm{~L}$.

Engelgrave Coelum Empireum $06 \mathrm{~s}$.

$16 \mathrm{~s}$.

$12 \mathrm{~s}$.

20 s.

$10 \mathrm{~s}$.

$16 \mathrm{~s}$.

$16 \mathrm{~s}$. $06 s$.

Bustamantinus de reptilibus

Biblia Sacra

Georgii Godelmani de Magnis

Disceptatio de Lapide phisico

Nicolaus Franchimont histo/rica medica

Lapis Lydius

Drauter Contiona semperparatus

Gregor i Michelis nota in $\mathrm{Ja} / \mathrm{cobi}$

Gafareli curiositates

Mendo Epitome

Samuelis Puphendori disertationes

C a s i m i r u s V u i j u k contionetor/extemporaneus

Eliani Varia historiae

Valerius Reginaldus de offcio/penitantis

\section{num.5Vitella en fol.}

\section{Gonzales Superdecretales}

Fragoso Regimen Reipublica

Quaresmii Elucidatio terra sancta

Bonaspei Theologia

Idem. Philosophia

Idem, de ignorantia suvinerrbili en 4

Peyrini opera

Theodoreh; et evagrii historia eccles ${ }^{a}$.

Socratis, et Sosomeni historiae Eccles ${ }^{a}$.

\section{num.6. Becerro en fol.}

num. 7.Perg ${ }^{\circ}$ en fol.

Mayolus dierum canicularium 2

Lohtner Biblioteca manualis 2

Maluenda opera 8

Aretoni Apocalipsim

Jacobi Pontani Symbola

Opingius de unisignium iura

Macri dictionarium 
Estante 9.num.1.Vitella en fol.

num.2.Becerro en $4^{\circ}$

\begin{tabular}{lll}
198 & 3L. $10 \mathrm{~s}$. \\
199 & 2L. $10 \mathrm{~s}$. \\
200 & 1L. \\
201 & \multicolumn{1}{c}{$16 \mathrm{~s}}$. \\
202 & \multicolumn{2}{c}{$16 \mathrm{~s}}$. \\
203 & 2L. \\
204 & 1L. $04 \mathrm{~s}$. \\
205 & 1L. \\
206 & 1L. $04 \mathrm{~s}$. \\
207 & \multicolumn{2}{l}{$12 \mathrm{~s}}$. \\
208 & IL. \\
209 & \multicolumn{2}{l}{$16 \mathrm{~s}}$.
\end{tabular}

$210 \quad 1 \mathrm{~L}$.

211 3L.

212 1L.

213 1L. 10s.

214

215

216 3L. 10 s.

217 2L.

218 2L. 10 s.

$219 \quad 2 \mathrm{~L}$.

220

$10 \mathrm{~s}$. 16 s.
$2 \mathrm{~L}$.

1L. $10 \mathrm{~s}$.

$12 \mathrm{~L}$.

$3 \mathrm{~L}$.

$1 \mathrm{~L}$. 
num. 6. Becerro en fol.

$23132 \mathrm{~L}$.

Barbosa

Crullench

Conrradi praxis beneficiaria

num.7.Perg ${ }^{\circ}$. en fol.

$10 \mathrm{~s}$.

Discurso juridico contra la Yglesia de

$10 \mathrm{~s}$.

S.Salvador, del Cabildo......

238 IL. 10s.

Memorial del Rey a Urbano 8

Pineda de rebus Salominis

Estante 10 num.1.Perg ${ }^{\circ}$ en fol.

$2397 \mathrm{~L}$.

Bosio Theologia moral

Arcones in

num. 3.Perg ${ }^{\circ}$. en $4^{\circ}$

2L. $10 \mathrm{~s}$.

Carsi questiones morales

Miscelanea de Fuster

num.4.Perg ${ }^{\circ}$ en $4^{\circ}$ y $8^{\circ}$

$04 \mathrm{~s}$.

Summa de Ledesma

$06 \mathrm{~s}$.

Erasmus de duplici copia verborum

Catecismo de Pio quinto

$06 \mathrm{~s}$.

Camiriano Concordia Sacrorum/Locorum

$03 \mathrm{~s}$.

Stephanus de Osculationes pe/dum S.Pontis.

Medicina moralis de

Libellus Suplex Carmelitanum

num. 5.Vitella en fol.

Predique de Oliva en italiano 4

Enrique Piringio in ius Canon. 5

Lesana opera

num.6.Perg ${ }^{\circ}$. en fol.

4L. $20 \mathrm{~s}$.

Philippe Dias Sermones

$08 \mathrm{~s}$.

Lucthprando de Lamays

$06 \mathrm{~s}$.

Questiones selectas de Crespi 
num.7.Perg ${ }^{\circ}$ en fol.

Estante 11.num 1.Perg ${ }^{\circ}$. en fol.

\section{Pinto Ramirez}

Deocumphs (Corregido encima Des Champs) de hareri Janunii

\section{$265 \quad 1 \mathrm{~L}$.}

$2661 \mathrm{~L}$.

$06 \mathrm{~s}$.

$08 \mathrm{~s}$.

06s.

$1 \mathrm{~L}$.

$12 \mathrm{~s}$.

$08 \mathrm{~s}$.

$12 \mathrm{~s}$.
2L. 10s.

$5 \mathrm{~L}$.

num. $2 \mathrm{Perg}^{\circ}$ en $4^{\circ}$

Ribadeneyra de Scientia Deil, vo/luntate Dei, et actibus humanis

Bernardini de Bustos.2.parte/sermones del Rosario

Gomez Iugum Luceferi

Facto Belgici, et Bungundia (Al margen:Mirai)

Vita Belarmini

num.3 Perg.en 4 y 8

Bernardini de Bustos maritate

Lorenço rtis de los 5 sentidos

Juan de Calderon fragmentun/chronici

Quaresma de muniessa

num.4.Perg ${ }^{\circ}$ en $8^{\circ}$

04s. Gavarri a los confesores

06s. Paulus Aretius de transmutationes/agua in sacrificio missa

08s. Roberti Belarmini institutiones/Lingu Hebraida

Nationes funebrae in exequiis/Philippi secundi

Barbosa de grandibus Ecclesiasticis

num.5. Vitella en fol.

A u bertus Mirreus

Biblioteca/Ecclesiastica

Plotii Biblioteca

Bolater comentariorum/urbanorum

Boni Merbeii (?)suma christiana 
$28526 \mathrm{~s}$.

286 IL. $02 \mathrm{~s}$.

28720 s.

288

289

290

291

292

$29310 \mathrm{~L}$.

294 20L.

295

296 1L. 20s.

$06 \mathrm{~s}$.

$3008 \mathrm{~L}$.

\section{$1 \mathrm{~L}$.}

303 3L. $10 \mathrm{~s}$.

304 4L.

305 1L. 04s.

$306 \quad 1 \mathrm{~L}$

num.6.Perg ${ }^{\circ}$. en fol.

Salon de Justicia, et iura

Catena Antonii Peretii

Velasques ad filipenses

\section{$\underline{\text { num.7 }}$}

Guevara otario de Religiosas 1

Montecalvario de Guevara

Diccionario historico, y poetico 1

Paradoxa moralis de ornatus mulierum 1

Petrus de Natalibus

Estante 12.num 1.Perg ${ }^{\circ}$ en fol.

Thomas Hurtado opera

6

Aye Arbor vita,et in exodum

Num.2.Perg ${ }^{\circ}$ en 4

Freyre in Indices

num3

Durandus Retionale

$\underline{\text { num } 4 \text { en } 4^{\circ}}$

Caravantes practica de missiones

num 5.Vitella en fol.

Constitutiones Eccles.Valentine 1

Castropalao opus morales 3

Ripalda de ente supremo,fide,/spe,et 4

Charitate

Idem en 4.super Magistrum

Sotuelo Biblioteca Scriptorum.Societate Jesu

Arries franco campus Eliseus 1

Paulus Arginus mosrs peccato/rum 2 perima

Nicolau Lombardus in es _ _ am / et 1

Hieremian

Peres in 2 et 3p.D.Thomas

Num 6.fol.Pergamino. 
$2 \mathrm{~L}$.

$12 s$.
$7 \mathrm{~L}$. $12 \mathrm{~s}$. IL. $10 \mathrm{~s}$. $1 \mathrm{~L}$.

$8 \mathrm{~L}$. $30 \mathrm{~L}$. $12 s$.

06s.

$04 \mathrm{~s}$.

$04 \mathrm{~s}$.

$04 \mathrm{~s}$.

$08 \mathrm{~s}$.

$06 \mathrm{~s}$.

$08 \mathrm{~s}$.

$12 \mathrm{~s}$.

$12 \mathrm{~s}$.
Diferentia Utrisque fori

Speleta de casibus moralibus

Estante 13.Perg ${ }^{\circ}$ en 4.u.2.

Ogea tract.moralis

Protuarium a Christo nato,uso/ad

Enricum Regen Gallie

\section{num.3.Perg ${ }^{\circ}$.en 4.}

Origen de las Pabordias

Catezismo de Camacho

1

$\mathrm{L} \mathrm{u} \mathrm{m} \mathrm{b} \mathrm{i} \mathrm{e} \mathrm{r} \mathrm{s} \mathrm{u} \mathrm{m} \mathrm{a,} \mathrm{y}$ proposiciones/condenadas

Figueroa Lucerna decretalium

num.5.Vitella en fol.

Sanchez opus morales

Antonii a Spiritu Sancto opera

4

Pontius de matrimonio

Cherubinus de vissionex perfecta

Racanius de Concept. Theolog.

Riccioli opera

num.6.Perg ${ }^{\circ}$. en fol.

Ruperti opera

Garcia Summa moral

Pernoge medulla S. Evangelii

P. Joannis Ruibrochii opera

num.7.Perg ${ }^{\circ}$ en fol.

Vazquez in S.Thomas 9

Suarez opera 5

Januarii resolutuines

num. 2.Perg ${ }^{\circ}$ en 4.

Sermones de Vega

Rodriguez de la Bulla

Hurtado de Justitia,et iure

Aquiles anno santo

Diez Super Evangelia

Summa Coleti

Dircurso contra las comedias

Manuale calificatorum

Luyngerus forum Philosophie/Poetica,2p. 


$\begin{array}{lll}337 & \text { 22L. } & \\ 338 & \text { 3L. } & \\ 339 & \text { 1L. } 10 s . \\ 340 & \text { 6L. } & \end{array}$

341

1L. 12s.

$8 \mathrm{~L}$.

343

344

345

346

347

348

349

350

$16 \mathrm{~s}$.

3L. $20 \mathrm{~s}$.

$26 \mathrm{~s}$.

$06 \mathrm{~s}$.

$08 \mathrm{~s}$.

$06 \mathrm{~s}$.

$06 \mathrm{~s}$.

num. 5.Vitella en fol.

Silveyra 10

Philippus Ferrarius lexicon geogra/phico Arignus triumphus penitentiae $\mathrm{P}$ i c c i o n a r d u s d e aprobationes/doctri.S.Thom.

num.6.Perg en fol.

Chronographia Genebrardo

Gassendus ethica epycurii philoso/phia et methereologia

num.7.Perg ${ }^{\circ}$ en fol.

Hieronymus ab oleatro in Pantateum.

Benedicti Pererii opera

$\underline{\text { Sobre la puerta } \text { Perg }^{\circ} \text { en } 4}$

Corpus veterum Poetarum

Summa Silvertina

Delrio in Cantica de Magia, et de adagiis sacris

16s. Bartholomeus a S.Fausto Speculum/confesionum Joannis Matheo historiarum in die

Viegas in apocalip

Estante $15 . \mathrm{n}^{\circ} 1$. Becerro en fol.

Laenirtii opuscula

La Aye in Apocalip.

Num.2 Becerra en varias formas.

Biblia Sacra en 16

Petrus Laynexus Colectio sen/tentiarum

16s. Exercitia Joannis Santerii

Raymundi Bonalii Theolg.moralis

Allosa alfabetum morale

Alpisqueta manuale de S. Gertrudis

Diccionario poetico

M. Tul. Ciceronis retori

Dionysius Alicarnasius de origenes/et antiquitate romanorum

D:Eusebii e _ iceni homini Evahg

Orationes diversas 
$06 \mathrm{~s}$.

Distica de moribus Catonis

1L. 16s.

Ollaya de mis Cant ${ }^{\mathbf{a}}$ y resada,y

$06 \mathrm{~s}$.

Ceremonial romano

$03 \mathrm{~s}$.

Ceremonial de Ximeno

$03 \mathrm{~s}$.

Regula Cleri

$06 \mathrm{~s}$.

Summa de Diana

370

$05 \mathrm{~s}$.

Ritualis Romani Pauli quinti

371

372

$06 \mathrm{~s}$.

Obras de Hoste

$04 \mathrm{~s}$.

Bustamante de Ceremonias

Examen de Indulgencias del/P.Sanchez

\section{num.5.Becerro en fol.}

$12 \mathrm{~L}$.

Engelgrave opera

Molina in S.Thomas

$37522 \mathrm{~L}$.

Num.6.Perg ${ }^{\circ}$ en fol.

$376 \quad$ IL.

Caramuelis opera

Expurgatorio

377 1L. 10s.

Macedus pro domus veritatis

378

379

$1 \mathrm{~L}$.

Lara de las tres gracias

Verde in Bullam Alexand.

num. 7.n.1.Becerra en $4^{\circ}$

380 5L. 20 s.

Sermones Pauleti

4

Sermones Calamati

Num.2.Becerro

1L. 20s.

Mathelo in Discoridem

Num. $3^{\circ}$ Perg ${ }^{\circ}$

04s. Remigio manuale confessionum

Belarmini opuscula

num.4.Becerro en $8^{\circ}$

Regulas et constitutiones soc.Jesu

$6 \mathrm{~L}$.

Engelgrave emblemeta

Viriderium Marianum a_vicen.

Eusbergio

Thesaurus Poetarum de Salas

Magister sententiarum

num.6.Becerro en fol. 
Scaherter opera

Vita Patrum orientis

396 3L.

P.Danetius Diccionarium latinum

397 5L.

Philippus Br_tius

$398 \quad 2 \mathrm{~L} .04 \mathrm{~s}$.

num.7.Perg ${ }^{\circ}$.en fol.

$39920 \mathrm{~L}$.

Adviento y quaresma de Hostensio 1

Angeli Pasienchelli opera 7

$400 \quad 6 \mathrm{~L}$.

- Lirei opera

Michael de Avendaño de Di/vina Scientia

$4023 \mathrm{~L}$.

Quartu in rub.misalis

$4035 \mathrm{~L}$.

Biblia sacra Lugdii año 1669

20 s.

num. 2.Perg' ${ }^{\circ}$. en $4^{\circ}$

405

$10 \mathrm{~s}$.

Petrus Rosello de Comunione anti-/qua inter Gallias et Hispanas

Sanchez in Cantica,in acta, et ima/ginibus Deorum

\section{num. 3.Becerro en 16}

406 3L. 12 s.

Enrichus Oldenburgio acto Oonei/Regia in Anglia

$408 \quad 16 \mathrm{~s}$.

Alianum de Anumalibus

Kircmanus de anpulri, et fa/neribus

Romam.

1L. $10 \mathrm{~s}$.

Forma dei

Jansenius inventa antigua

Pinciri (o Pincioni) enigmata

$10 \mathrm{~s}$.

Schola Curiositatis de Antonio/Melara

Petrarcha de Utriusque remedis fortuna

$20 \mathrm{~s}$.

$415 \quad 06 \mathrm{~s}$.

Polidor Virgilius de rerum/inventeribus

Combate espiritual en frances

$08 \mathrm{~s}$.

417 1L. 20 s.

num. 4.Perg ${ }^{\circ}$ en 8.

$418 \quad 2 \mathrm{~L}$.

Mayolus dies canicularum

Dionysius Cartusianus de suma/fidei,y 4 contra el Alcoran

num. 5.Bec.en fol. 


$\begin{array}{lll}420 & \text { IL. } & 20 \text { s. } \\ 421 & \text { 1L. } & \\ 422 & \text { 1L. } & 10 \text { s. }\end{array}$

423

424

425

426

427

428

429

430

431

432

433

434

435

436

437

438

439

440

441

442

443

444

445

446

447

448

449

450

451

$452 \quad 100 \mathrm{~L}$ num. 6.Perg ${ }^{\circ}$. en fol.

Marci maximi cronicon

Casianus privilegia regularium

Dionisius Alicarnasium de an/tiuitate Romanorum

num.7.Bec ${ }^{\circ}$.en fol.

Fauleri opera.

Plinii opera

Soto de Justitia,et Iure

Gesneri opera

Divi Anselmi opera

Estante de dentro den diver/sas formas=

Conmenctator Marianus a/Theofilo Ray_ndo

Sinodo del Señor Aliaga

Consilio Provinsial de Valencia de Ayala

Epitome del sino del/señor Aliaga

Sinodo del Señor Ayala

Leonardo de Murcia disquis./morales

Alphonsus Fernandez conceptatio praedicatoria

Grandezas de Girona

Memoriales varios

Valerius Maximun in $4^{\circ}$

Ajelius in quarto

Pasqualigo de franc

Pascualigo Questiones canonicas

Pasqualigo praxis theoricas/moralis

Pasqualigo questiones morales

Pasqualigo praxis Jeniunii(sic)

Pasqualigo de sacrificiis

Pasqualigo Sacra Specular/doctrina

Pasqualigo de Jubileo

Caramuel Theolga fundamental

Caramuel Theolog ${ }^{\mathrm{a}}$ Regul.

Caramuel Logica moralis

Caramuel de resxtrictione

Mas en de Octubre se llevo/el Señor

Arçobispo todas las obras de Bolando

Juego de los concilios Generales en folio 


\section{Autores y títulos de obras}

Acta eruditorum, 31 .

Alexander ab Alexandria, 46.

Aliaga, 438.

Aliano, 407.

Alpisqueta, 358.

Alva y Astorga, Pedro de, 35, 37.

Aller, 200.

Alliers, 144.

Alloza, Juan, 357.

Amelus, 136.

Amiano, Marcelino, 214.

Ancharano, Pedro, 154.

Anselmo, San, 427.

Aquiles, 331.

Arcones, Andreas Lucas de, 240.

Arduia, Ricardo, 213.

Aretio, Pablo, 275.

Aretio, Benedicto, 192.

Argelio, Juan, 438.

Arigno, Pablo, 304, 339.

Arriaga, Rodrigo, 132.

Arries, 203.

Arsdekin, Ricardo, 225.

Ausonio, Decimo Magno, 124.

Avendaño Estenaga, Miguel, 401.

Ayala, Martin Perez de, 430.

Aye, La, 294, 352.

Barbosa, Agustin, $231,278$.

Barisano, Francesco Domenico, 160.

Bartoli, Daniello, 96.

Bartolomeo, Fausto a San, 348.

Baseo, Eligio, 107.

Bauny, Etienne, 197.

Bausi, 207.

Belarmino, Roberto, 58, 276, 384.

Benedicto Justiniano, José, 83.

Bernardino de Siena, San, 39.

Biblia Sacra, 82, 152, 166, 353, 403.

Blasio de Parma, 14.

Boecio, Anicio Manlio Torcuato 
Bolando, Jean, 451.

Bolater, 281.

Bona, Giovanii Cardenal, 211, 282.

Bonal, Raimundo, 357.

Bonaspei, Nicolas, 181, 182, 183.

Boucat, Antonio, 34.

Burgense, Lucas, 91.

Busenbaum, Hermann, 81.

Bustamante de la Camara, Juan, 165, 361.

Busti, Bernardino de, 266.

Calamati, 381.

Calderón, Juan Alonso, 197, 272.

Calixto, Federico Ulrico, 199.

Camacho, Juan, 312.

Camiriano, 246.

Caramanuel de Loblokowitz, Juan, 447, 448, 449, 450.

Caravantes Anonymus, 297.

Carderia, 7.

Caria, 112.

Caritius, 50.

Carleton, Thomas Compoton, 67.

Carriere, François, 106.

Carsi, 241.

Casalas, Jean, 146.

Casia, Simon, 6.

Casimiro Vuijuk, 16, 146.

Caspense o Caspe, Luis, 283.

Cassianus, Juan, 2, 3, 421.

Castillo, Martin del, 52.

Castillo Velasco, Francisco, 239.

Castro Palao, Fernando, 299.

Catena o Cadena, Ludovico de la, 90.

Catezismo, Pio V, 245.

Caton, Martino Garcia, 364.

Causini, 223.

Cesatus, 217.

Ciceron, Marco Tulio, 59, 360.

Civilli, Antoii, 145.

Claudinus, Giulio Cesare, 22, 208.

Coleti, L. 333.

Combate espiritual, 415.

Comei, 86.

Concilios Generales, 452.

Concondantiae Biblorum, 216. 
Conrado, Pedro, 223.

Constitutiones Ecclesia Valentina, 298.

Cordoba, Juan Rodolfo, 90.

Crespi Borja de Valdaura, Luis, 256.

Crullench, 232.

Cruz, Juan de la, 111.

Curcio, Quinto, 17.

Cherubin d'Orleans, P., 318.

Chronographia Genebrardi, 341.

Chumacero y Carrillo, Juan, 236.

Damianus, 128.

Danet, Pierre, 396.

Del Río, Martin Antonio, 347.

Deschamps, Stefano, 264.

Desmonena, Carlos Nicolas, 65 .

Diana, Antonio, 368.

Diaz, Felipe, 254.

Dicastillo, Juan, 337.

Diccionario poetico, 359 .

Diccionario Histórico y poético, 290.

Diez, Felipe, 332.

Diferencia utriusque Fori, 307.

Diogenes, Laercio, 247.

Dionisio Alicarnaso, 361, 418.

Dionisio Cartujano, 28, 418.

Disceptatio a Lapide phisico, 168.

Discurso contra las comedias, 334.

Discurso juridico contra la Iglesia de

Dozzy, Lucas, 163.

Drauter, 171.

Ducange, Charles Dufresne, 143.

Durando de Santo Pacian, 262.

Durante, Guillermo, 296.

Eliano, 176.

Enao, 134.

Engelgrave, Enrique, 164.373.

Epifanio de Salamina, 140.

Epigramatus delectus, 99.

Erasmo, Desiderio, 244.

Erasmo, Bartolino, 209.

Erber, 33.

Ertis, Lorenzo, 271.

Espiritu Santo, Antonio, 316.

Eusbergio, 388. 
Eusebio, 224.

Expurgatorio, 376.

Fabri, Felipe, 409, 410.

Fabro Stapulense, Jacobo, 25.

Faulei o Fauleri, 423.

Fedelri, 122.

Fernandez, Alfonso, 434.

Ferrant, 13.

Ferrari, Felipe, 338.

Ferrer, San Vicente, 150.

Fictio, 222.

Figueroa, 314.

Forei, 205.

Forma Dei, 409.

Fragoso, Juan Bautista, 179.

Franchimont de Franckenfeld, Nicolás, 169.

Freyre, 294.

Fuster, Melchor, 292.

Galatino, Pedro, 261.

Galberio, 80.

García, Nicolás, 51, 323.

Gassendi, Pedro, 342.

Gavarri, 274.

Georgii Gödelmann, Johann, 167, 204.

Georgio de Rodas, 188.

Gervasio o Gervatius, Gaspar, 159.

Gesnier, Conrado Juan, 212, 426.

Gimenium, Amadeo, 86.

Gober Vander Eembd, 76.

Gomez, 267.

Gonzalez, Manuel, 178.

Gotstebschii, 125.

Grandezas de Gerona, 435.

Gregorio, Miguel, 172.

Gregorio, el Magno Papa San, 112.

Guevara, Antonio de, 288, 289.

Hartmann, Philipp Jacob, 268.

Hautesserre, Antoine Dadine, 201.

Hepten, 85.

Hermes, 136.

Hichessi, 219.

Hortensio Felix Paravicino, 398.

Hugo de Saint Chaiz, Cardenal, 71, 84.

Hurio, 342. 
Hurtado de Mendoza, Tomas, 293.

Hurtado, Gaspar, 330.

Irgume, Juan, 199.

Janssen, 410.

Januarii, 327.

Jeronimo, San, 343.

Josepho, Jeronimo de San, 230.

Journaux des Travaux, Les, 120.

Juvenal, Decio Junio, 20.

Kircher, Atanasio, 196, 408.

Labbe, Felipe, 161, 419.

Langio o Laugio, 284.

Lanirtii, 351.

Lañis, 127.

Lapide, Cornelio, 227.

Lara, Alfonso Perez de, 54, 55, 378.

Laurenti, José, 71, 228.

Laurio, Laurentio Bracantio de, 284.

Laynerus, 354.

Le Grand, Antonio, 32.

(Le jornale descavone)

Ledesma, Martolome de, 243.

Lezana, Juan Bautista de, 253.

Libellus Suplex Carmelitanus, 250.

Lirei, Opera, 400.

Livio, Tito, 18, 77.

Lohner, Tobias, 105, 385, 391.

Loleti, 141.

Lombardo, 305.

Loyola, San Ignacio, 215.

Luca, Giambatista de Cardenal, 116.

Lucano, Marco Anneo, 100.

Lucerna, 56.

Luitprando, 255.

Lumbier, Raimundo, 313.

Lupo, Christian, 40, 41, 42, 43.

Lusana, 260.

Macedo, Antonio, 377.

Machado, Francisco, 135.

Madrid, Jose, 69.

Magaliano, Cosme, 56.

Magister, Sententiarum, 390.

Maiolo, Simon, 189.417.

Maluenda, Tomas, 191. 
Marcantii, Jacobo,

Marcelinus, 68.

Marci de Kronland, Marcos, 195, 420.

Marcial, Marco Valerio, 23, 98.

Mateu y Sanz, Lorenzo, 133, 382.

Mateu, Rufi, 103.

Matheo, Johannis, 349.

Melara, Antonio, 412.

Memoriales varios, 435 .

Mencarii, Francisco, 97.

Mendo, Andres, 118, 173.

Miraeus, Aubertus, 268, 279.

Miscelanea curiosa medico fisica, 30 .

Molina, Luis de, 374.

Monarquia mistica, 92.

Mulerus, 202.

Muniesa, Tomas, 273.

Murcia, Leonardo de, 433.

Muret, Marco Antonio, 151.

Nationes (u Orationes) in exequias

Nicolaus, 169.

Niërember, Juan Eusebio, 130.

Octaviario, en portugues, 8.

Ogea, Pedro de, 309.

Olay, 121.

Olaya, 365.

Oldenburgo, Henry, 406.

Oliva, 251.

Opingio, 194.

Orationes diversas, 363 .

Origen de las Pabordias,

Ovidio Mason, Publio, 45, 114.

Palacios, Miguel, 218.

Papinio Estacio, Publio, 123.

Paradoxa Moralia de ornatus mulierum, 291.

Partidas Las, del rey Alfonso X, 108

Pascualigo, Zacarias, 439, 440, 441, 442, 443, 444, 445.

Pasianchelli, Angelo, 399.

Pauleti, 380.

Paulino de Nola, San, 149.

Peponte, 198.

Perez, Jeronimo, 129.

Perez, Antonio, 306.

Pernoge, 323. 
Petavio, 142.

Petrarca, Francisco, 413.

Petrus Lusus, 416.

Petrus de Insula, 292.

Pexenfelder, Michael, 148.

Peyrinis, Laurencio de, 184.

Piicionardo, 12, 340.

Pilippi Secundus, 277.

Pimentel, Domingo, 236.

Pincioni, 411.

Pineda, Juan de, 109, 110, 238.

Pinto Ramirez, 263.

Piringio, Enrique, 252.

Plinio Cecilio Segundo, Cayo, 61, 62, 63, 424.

Plotii, 280.

Polidor, 414.

Ponce de Leon, Basilio, 317.

Pontano, Jacobo, 193.

Porevino, 115.

Porta, Giambattista della, 64.

Prontuario, 310.

Prudencio, Aurelio Clemente, 104.

Pufendorf, Samuel, 170.

Quarti, Paulus Maria, 206, 403.

Racanius, 319.

Raynaud, Teofilo, 187, 428.

Regia Parnasi, 210.

Reginaldo, Valerio, 153, 177.

Regulae generales et constitutionibus Societatis Jesu, 386.

Remigio, 383.

Respuesta al abuso de los escohotados, 258-259.

Ribadeneira, Gaspar, 265.

Riccioli, Pedro Andres, 320.

Ripalda, Jerónimo de, 300, 301.

Rituale seu Manuale Romanum Pauli V, 369.

Rodriguez, Jacobo, 221.

Rodriguez, Manuel, 329.

Rosell, Jose, 101.

Rosello, Pedro, 404.

Ruisbrochio, Juan, 324.

Ruperti, 321.

Salamo, Simon, 367.

Salas, Juan de, 389.

Salon, Miguel Bartolomeo, 285. 
San Salvador, 235.

Sanchez, Tomas, 315, 372.

Sanchez, Gaspar, 29, 405.

Sandeo, Felino, 10, 224.

Sanlerii, Juan, 355.

Sayro, Gregorio, 131.

Scarberter, 394.

Schelstrate, Enmanuel, 24.

Schott, Gaspar, 155.

Segovia, Juan, 36.

Seneca, Lucio Annes, 60, 226.

Severino, 21, 66.

Silos, José, 88.

Silvii, Eneae, 138.

Solano de Luque, 170.

Solino, Cayo Julio, 137.

Soto, Domingo, 425.

Sotuelo, 302.

Sozomeno, Hermij, 186.

Speleta, 308.

Stephano, Jose, 94, 156, 248.

Suarez, Francisco, 326.

Suetonio Tranquilo, Cayo, 19.

Suma Silvestrina, 346.

Sylveira, Miguel, 337.

Tacito, Cayo Cornelio, 76.

Theodoren, 185.

Therillus, Antonio, 157.

Torrecillas, Martin, 335.

Valens o Valente, Francisco, 15.

Valeriano, 38.

Valerio Maximo, Publio, 47, 437.

Valles, Jose, 72.

Vázquez, Gabriel, 325.

Vega, Diego de, 75, 94, 257, 328.

Velázquez, Juan Antonio, 287.

Verde, Francisco, 379.

Viegas, Blas, 350.

Vilanova, Tomas, Santo, 203.

Villagrasa, Francisco de, 119.

Villalpando, Juan Bautista, 139.

Virgilio, Marcon, Publio, 44.

Vita Patrum Orientis, 395.

Vita Belarmini, 269. 
Vivien, Miguel, 147.

Vosio, Gerardo, 239.

Weber, Fortunato, 234.

Ximeno, 366.

Zamora, Laurencio, 93. 


\section{NOTAS}

1.- GARCÍA GÓMEZ, María Dolores: El Arzobispo de Valencia Folch de Cardona: análisis de una biblioteca eclesiástica del siglo XVIII. Alicante, 1996.

2.- GARCIA GÓMEZ, María Dolores: "La biblioteca de Melchor de Macanaz. Estudio de una biblioteca político-juridica". (En prensa)

3.- B.N. Mss. 8.397, (V-138).

4.- ALEIXANDRE TENA, F.: "Libro, Imprenta y Censores en Valencia bajo Carlos II". Homenaje al Doctor Sebastić García Martínez. Valencia, 1988. p. 172.

5.- B.U.V. Sermones Fúnebres. Varios, 215.

6.- B.U.V. Sermó de la Conquista de la Molt Insigne, Leal e Coronada Ciutat de Valencia. Vaiencia, Geroni Vilagrasa, 1666.

7.- B.U.V. Sermones Fúnebres. Varios, 215, Réplica al Sermón del Doctor Cardona, por el Dr. José Leonardo Esteve.

8.- ojo

9.- RUPERT HALL, A.: La revolución cientifica. 1500-1750. 1985. GEYMONAT, L.: Historia de la Filosofia y de la Ciencia. 1985. LÓPEZ PIÑERO, J.M.: Op.cit. NAVARRO, V.: Op.cit.

10.- Apud. NAVARRO, V.: Op. cit., p. 50.

11.- Acta Eruditorum. Leipzig. 1681-1728. - № 31

12.- Journals des Ş̧avants - Paris. 1655. - No 120.

13.- Apud. Rupert HALL, A.: Op. cit., p. 346.

14.- Miscellanea Curiosa. 1670-1706. - №30.

15.- Philosophicals Transactions. 1665. - № 406.

16.- Conrado Gesner. 1545. - No 212.

17.- P. Gaspar Schott. 1664. - No 155.

18.- Albert von Haller. 1667. - $\mathrm{N}^{\circ} 200$.

19.- ALVAREZ DE MORALES, A.: La llustración y la Reforma en la Universidad Española del siglo XVIII. 1969., p. 137. LÓPEZ PIÑERO, J.M.: Medicina Historia Saciedad. 1979., pp. 169-173.

20.- Nicolas Franchimont. Lithotomia medica sen Tractatus lithontripticus de calculo renum er vesicae. 1683. - No 169.

21.- Philipus Jacobus Hartmann. 1648-1699. - N²68. 
22.- $P$. Antoine Le Grand. Historia naturae variis experimentis et raciotinis elucidata secundum principia stabilita in Institutione philosophicae. 1673. - $\mathrm{N}^{\circ} 132$.

23.- Atanasius Kircher. Ars Magna lucis et umbrae. 1644. - № 196.

24.- Henry Oldenburg. Acta Philosophicae Societatis Regiae in Anglia. 1665. - No 406.

25.- Apud. Rupert HALL, A.: Op. cit., pp. 319-333.

26.- Apud. Rupert HALL, A.: Op. cit., p. 395.

27.- P. Cherubin D'ORLEANS. La vision parfaite ou le concours de deux axes de la vision en un seul point de l'object. $1677 .-\mathrm{N}^{\circ} 318$.

28.- Joham Marcus Marci de Kronland. 1595-1667. - № 420.

29.- Erasmus Bartholin. "De naturae mirabilibus". 1674. - № 209.

30.- Jansen. G. - N ${ }^{\circ} 410$. Hemos desechado la opción del autor del Augustinus por no tener éste ninguna obra atribuible con el enunciado del inventario: la del optico holandés, de importancia en su momento, tampoco es verificable.

31.- Oliva, Antonio.: "De Natura Iridis". I650.- № 251.

32.- Caramuel de Loblokowitz. Juan. 1602-1682. - Núms. 447-448-449-450.

33.- Eusebio Nieremberg, Juan.: "Historia naturae maxime peregrinae". 1635. - No 130.

34.- Bustamante de la Cámara, Juan.: "De reptilibus vere animantibus S. Scripturae". 1595. - No 165.

35.- Apud. GEYMONAT, L.: Op. cit., p. 67.

36.- Apud. Rupert HALL, A.: Op. cit., p. 27.

37.- Godelman, Johan Georg.: Tractatus de magiis, veneficiis et lamis. 1591. - N'167.

38.- Pexenfelder, Michael. Ethica symbolica e fabularum umbris. 1682. - $\mathrm{N}^{\circ} 148$.

39.- Schott, Caspar. Thecnica curiosa. 1664. - $\mathrm{N}^{\circ} 155$.

40.- Apud. Rupert HALL, A.: Op. cit., pp. 343-391.

41.- $N^{o} 168$.

42.- Giambatista della Porta. Magiae naturalis sive miraculis rerum naturalium. 1589. - No 64.

43.- Caravantes, A.: Praxium huisce artis quam cum aliquot ut loquitur vera Alchimiae. 1561. - $\mathrm{N}^{\circ} 297$.

44.- Martín Antonio del Rio. Disquisitionum magicarum libri sex. 1612. - № 347.

45.- Apud. LÓPEZ PIÑERO, J.M.: Op. cit., p. 21.

46.- Erasmo de Rotterdam, Desiderio : De duplici copia verborum ac renum comentarii duo ab autore 
ipso diligentisima recogniti et emaculati atque in impeerisque locis aucti. 1514. - $\mathrm{N}^{\circ} 244$.

47.- BATAillon, Marcel. Erasmo y España. 1966., p. 717.

48.- FAYARD, J.: Los miembros del Consejo de Castilla (1621-1746). 1982., p. 471.

49.- San Jerónimo. Doctor Ecclesiae. Opera plurima. - № 343.

50.- San Epifanio. Opera. - $\mathrm{N}^{\circ} 140$.

51.- San Paulini Episcopi Nolani. Epistolae et poemata luculenta. 1622. - No 149.

52.- Apud. BATAILLON, M.: Op. cit., p. 27.

53.- San Bernardino Senensis. Opera multa. 1591. - No 39 .

54.- San Gregorio de Tours. Opera omnia necnon Fredegarii scholastici epitome et chronicum cum suis continiatoribus et aliis antiquiis monumentiis ad codices manuscriptos et veieres editiones collata enmendata et aucta atque notis et observationinus illustrata opera et studio. 1699. $-\mathrm{N}^{\circ} 112$.

55.- Núms. 112, 140, 427.

56.- Núms. $82,152,166,353,403$.

57.- Hugo de Saint-Chair. Concordantiae Biblorum utriusque Testamenti Veteris et Novi perfectae et integrae. 1585. - $\mathrm{N}^{\circ} 216$.

58.- Juan Bautista de Lucca, Cardenal. Correctiones ad Concordantiae biblorum. - No 116.

59.- Núms. 21-66, 60-226, 413.

60.- Apud. BATAILLON, M: Op. cit., p. 50

61.- Catonis Disticha moralia cum scholis. 1593. - N0 364.

62.- Marcelino Amiano. De rerum gestarum Libri XXXI. 1553. - $\mathrm{N}^{\circ} 214$.

63.- Jacobo Spanmuller, Pontano. Symbolicarum Libri XVII. - $\mathrm{N}^{\circ} 193$.

64.- Muret, Marco Antonio. Orationum Ciceronis in Catiliniam explicatio. 1557. - No 151.

65.- C. Julio Solino. Rerum totum urbe memorabilium thesaurus locupletissimis. 1543. - № 137.

66.- Los núms. 17, 18, 19, 20,21, 22, 23 corresponden a las obras de Juvenal, Quinto Curcio, Marcial. Tito Livio, Suetonio y Boecio y en ellos se especifica "ad usu delphini": Esta aclaración las señala como las mejores ediciones latinas, excepto las princeps y en el caso de Quinto Curcio la de Basilea en 1571 que incorporaba las notas de Erasmo.

67.- Núms. 20, 23-98, 123, 47-437, 147, 247.

68.- Corpus omnium Veterum poetarum latinorum. 1640. - $\mathrm{N}^{\circ} 345$.

69.- Podría despejar esta obra la duda sobre su edición en las del s. XV (Palau), que Vindel afirma de 
1479. Palau sólo da una en Castellano a partir de 1792.

70.- Núms. 76, 18-77, 100, 19, 61-62-63-424, 17, 361-418.

71.- BATAILLON, M.: Op. cit., p. 27.

72.- Núms. 72, 195, 290, 359, 396.

73.- Dufresne Du Cange. Charles. Glossarium ad scriptores mediae et infima graecitatis accedit appendix ad glossarium mediae et infima latinitatis. $1688-\mathrm{N}^{\circ} 143$.

74.- Roberto Belarmino, Pontiano. Institutiones linguae hebraicae. $1606-\mathrm{N}^{\circ} 58,276,284$.

75.- Vosio, Gerard. Institutiones Linguae graecae. 1642. - $\mathrm{N}^{\circ} 239$.

76.- MESTRE, A.: Religión y Culiura en el siglo XVIII. 1979., p. 684.

77.- Aeliano variae historiae Libri XIII. 1555. - № 176.

78.- Maluenda, Tomas de. Opusculum Hebrea Voce Hosanna. 1587. - No 191.

79.- Apud. NAVARRO, V.: Op. cit., p. 51; GARCIA MARTÍNEZ, s.: Op. cit., p. 153.

80.- P. Jean Bolland. Acta Sanctorum: Thesaurus Eclesiasticae Antiquitatis et Sacra etc Prophana eruditionis. 1643. - $\mathrm{N}^{\circ} 451$.

81.- Gassendi, Pierre. De vita moribus et doctrina Epicurii. 1647. - № 342.

82.- Labbe, Felipe. Bibliotheca Bibliothecarum curis secundis auctior. 1664 - No 161.

83.- Apud. García MARTINEZ, S.: Op. cit., p. 148.

84.- MESTRE. A.: Historia, Fueros y Actindes Politicas. Mayans y la Historiografia del XVIII. 1970., p. 311 .

85.- Labbe. Felipe. Elogium Divi Augustini umbra eiusdem tumulus novae doctrinae epithaphium. 1652. Elogia Sacra Theologica el philosophica regia eminentia illustria, historica poetica miscellanea. 1664 . $N^{\circ} 419$.

86.- Schelestrate, Emmanuel de. Antiquitas illustrata circa Concilia Generalia et provincialia decreta et gesta pontificcum et praecipua totius historiae ecclesiasticae capita. $1678 .-\mathrm{N}^{\circ} 24$.

87.- Felipe Labbe. Conciliorum Omnium Generalium et provincialium. Collectio Regia. 1664. - $\mathrm{N}^{\circ} 452$.

88.- Puffendorf, Samuel. Disertationes academicae selectiores. $1675 .-N^{0} 174$.

89.- Juan Bona. Cardenal. - No 211.

90.- MESTRE, A.: Ilustración y Reforna de la Iglesia. Pensamiento político religioso de D. Gregorio Mayans. 1968., p. 388.

91.- Hugo de Saint-Cher. Opera omnia in Universum Vetus et Novum Testamentum. 1645. - Núms. 71-74. 
92.- Cristiano Lupo. - Núms. 40, 41, 42, 43.

93.- GARCÍA GÓMEZ, Mal Dolores: Op. cit.

94.- Apud. FAYARD, J.: Op. cit., pp. 464-467.

95.- $\mathrm{N}^{\circ} 403$.

96.- Núms. 73, 108, 113, 119, 200, 203, 235, 237, 256, 258, 259, 271, 274, 288, 289, 290, 297, 311, 312 , $313,334,359,366,372,378,398,429,431,432,435,437$.

97.- Núms. 8, 11.

98. - No 415.

99.- No 430. 